\title{
Survival of submerged rice in a flood-prone region of West Africa
}

\author{
Jun-Ichi Sakagami* and Naoyoshi Kawano \\ Japan International Research Center for Agricultural Sciences, 1-1 Ohwashi, Tsukuba, 305-8686 \\ *Corresponding author: Tel/Fax: +81-29-838-6368/-6355, E-mail: sakajun@affrc.go.,jp
}

\begin{abstract}
Because of natural disasters caused by a heavy rain and change of precipitation pattern, rice production in West Africa is often unstable, whereas rice is an important food crop. Reports of flooding damage to rice plants have been increasing with the expansion of rainfed lowland rice cultivation there since 1988. This report reviews recent environmental changes that have occurred in a flood-prone region of West Africa, and the eco-physiological survival strategies used by rice plants under flooding stress. We identify the flooding status in West Africa, with flood-prone areas that are classifiable into three types: floating, deepwater, and flash flood areas. Most rice cultivars show shoot elongation in response to submergence. Shoot elongation during long-term submergence is an 'escape strategy', which enables rice to resume functioning when again in aerobic conditions. However, some rice genotypes can survive in flash flood areas due to tolerance to short-term submergence. The ecological and physiological traits of flash flood-tolerant rice include less chlorosis and high carbohydrate reserve storage, although shoot and leaf elongation are slow during submergence. Especially for flood-prone areas, we report the potential adaptability of Oryza glaberrima Steud., one cultivated species of rice originating from Africa, which has unique traits of increased biomass production through high photosynthesis by newly developed leaves under prolonged submergence. We conclude that stable agricultural systems with useful tolerance to flooding stress should be improved grain yield to mitigate submergence damage to rice crops in West Africa.
\end{abstract}

Key words: ecophysiology, flash floods, glaberrima, submergence, west Africa

\section{INTRODUCTION}

Rice farming in Africa began approximately 3500 years ago (Porteres 1970). The rice variety cultivated at the time was African rice (Oryza glaberrima Steud.), which is native to the continent (Chu and Oka 1972). African rice is well adapted to the severe local climate, but it has had little opportunity to be improved or selected by humans. It is therefore regarded as wild and of low productivity. For that reason, Asian rice (O. sativa L.) accounts for a high proportion of the rice consumed in Africa today. However, the development and promotion of a NEw RIce for AfriCA (NERICA) is attracting attention in Africa. Moreover, the properties of African rice, which was employed as a parent strain in the production of NERICA, are now being reassessed. In this manner, rice farming in Africa has been developed differently from that in Asia, and cultivation and cooking methods also differ in many ways. Farmers cultivate rice in irrigated lowlands in Asia, although rainfed uplands in Africa account for most rice fields. African farmers attach great importance to the quantity immediately after cooking in many cases (Sakagami et al. 2008). Although rice consumption in African countries has shown an increasing trend in recent years, the production rate is not sufficient to meet the demand. The volume of imported rice is increasing annually, which is having a detrimental effect on African countries' economies.

To resolve these issues, rice production yields must be increased, either by expanding the production area or by improving yield per unit of area. Realization of this goal is impeded primarily by the poor agricultural environment and unsophisticated agricultural technologies prevailing in Africa. In addition, farmers account for $80 \%$ of the population in African countries and make up a greater proportion of those below the poverty line than in Asian countries. It is therefore difficult, even for rice farmers, to acquire sufficient equipment and 
materials to produce rice rationally using best practices. In this respect, unlike the intensive rice farming that has become successful in Asian countries, to facilitate rice farming in Africa as a sustainable enterprise, it will be crucial to systematize low-input rice farming technology. In this light, we specifically examined the potential agricultural productivity of wet lowlands in the floodplains that are widely distributed throughout West Africa. Rice productivity in these wet lowland areas is much higher than that in the upland fields in terms of soil fertility and water availability, and unused areas of wet lowlands extend throughout river basins (Asubonteng et al. 2001). Accordingly, efficient utilization of wet lowlands could be an extremely effective means of resolving food problems in many areas of Africa (Sakagami et al. 2010). However, floods often inhibit rice growth through excessive water stress. Reports of flooding damage to rice plants have been increasing with the expansion of rainfed lowland rice cultivation there since 1988 (Hallegatta et al. 2010).

In general, rice cultivation is vulnerable to natural disasters in West Africa. One reason is the shortage of suitable irrigation systems. The area of irrigation is about $20 \%$ of the total area of rice cultivation, and most rice is planted in rainfed regions (Balasubramanian et al. 2007). Therefore, rice cultivation in West Africa is strongly influenced by precipitation or overflow from rivers. However, the status of damage to rice plants by flooding in West Africa has not been understood well until now. Upland rice is severely influenced by rainfall because of the lack of standing water. Yields of upland rice are very low (around $1 \mathrm{t} \mathrm{ha}^{-1}$ ) compared with those of lowland rice cultivation (around $2 \mathrm{t} \mathrm{ha}^{-1}$ ) (Norman and Otoo 2003). Lowlands therefore offer greater potential for raising rice production, and represent about 20-50 million hectares, depending on the definition used. At present, only about $10-20 \%$ of this area is under cultivation (Africa Rice Center 2004), thereby offering great potential for rice farming expansion. However, rice plants in lowland areas are often damaged by floods caused by heavy rain. It is therefore important to study the effects of submergence on rice plants to develop sustainable rice production in West Africa.

Flooding imposes severe selection pressure on plants, principally because excess water in their surroundings can deprive them of access to certain basic resources: oxygen, carbon dioxide, and light for photosynthesis. It is a major abiotic influence on species' distribution and agricultural productivity worldwide. Strong submergence-induced elongation is a common escape mechanism and one that helps submerged individuals regain or retain contact with the aerobic environment on which they depend (Jackson 2008). However, the submergence tolerance gene, $S u b-1 A$, uses a different strategy, depressing shoot elongation under short-term submergence to survive. Considering the circumstances of climate change and unstable environmental conditions in West Africa, the ability to tolerate flooded conditions is a major constraint on sustainable agriculture in the region. This paper presents a review of the current state of knowledge related to the survival mechanisms of rice plants in flood-prone regions of West Africa.

\section{Rice cultivation environment in West Africa West African Climate}

The climate in Africa is controlled by the Inter-Tropical Convergence Zone (ITCZ). Southeast trade winds (originating from the southern hemisphere) and northeast trade winds (originating in the northern hemisphere) come together near the equator (Nicholson 2009). Around the ITCZ, the atmosphere is unstable, and updrafts develop easily, thereby producing heavy rains on the south side of the ITCZ (Fig. 1) (Sultan and Janicot 2000). The seasonal change of the rainy season and dry season results from the movement of the ITCZ from south to north. Following the seasonal excursion of the sun, the ITCZ precipitation band goes north and reaches its northernmost position in August. Subsequently, it moves southward and reaches its southernmost position in January. Annual precipitation is around $4000 \mathrm{~mm}$. Furthermore, $80 \%$ of the annual precipitation is concentrated in the 4 months of June-September in Conakry in Guinea. Therefore, rice plants in this region often suffer heavy damage from floods.

The movement of the ITCZ is often erratic, engendering many unexpected seasons of drought and heavy rain episodes in Africa. In 2003, the ITCZ moved northward with greater velocity than normal and reached a more northern area ( $20.5^{\circ}$, inclined northward by $1.4^{\circ}$ ) than in a normal year (Kadomura 2005). This movement of the ITCZ caused severe floods by heavy rain in the West Sudan - Sahel zone from Chad to Senegal. In stark contrast, drought caused by the shortage of rainfall occurred in parts of Liberia to southern Nigeria in coastal Guinea. Agriculture in Africa depends mainly on rainfall and groundwater. Therefore, floods are currently causing severe problems for food production as well as rice in various regions (Futakuchi 


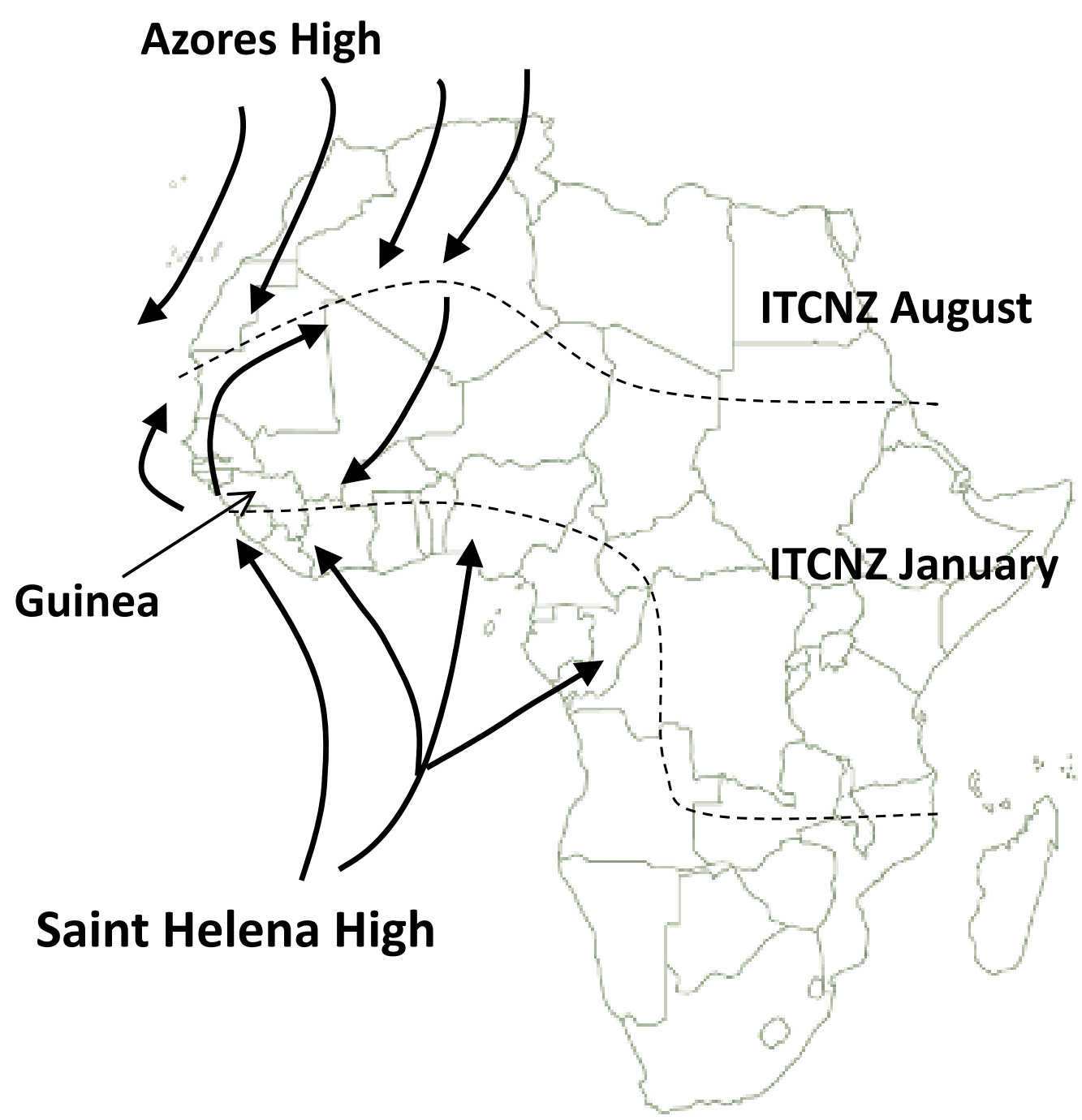

Fig. 1. Maps of the mean position of the ITCZ over Africa (Revised from Nicholson 2009)

2005). It is important to establish an agricultural system that is not shaken by climate change to ensure stable food production in the future.

\section{Rice ecosystem in West Africa}

The rice ecosystem in Africa is divisible into two main types: upland and lowland (Table 1). Upland rice is defined as rice grown on both flat and sloping fields that are not bounded (DeDatta 1975), which results in a high risk of water shortage and drought. Lowland rice is cultivated using standing water. Types of cultivation are classifiable into irrigated lowlands, rainfed lowlands, deepwater, and mangrove swamps according to the water

Table 1. Rice ecosystem in West Africa

\begin{tabular}{llll}
\hline Major ecosystem & Sub ecosysntem & Major constrains in water stress & Typical region \\
\hline Upland & Mountain slop & Drought & Ivory Cost, Sierra Leone \\
& Plateau & Dorught & Ghana, Guinea \\
Lowland & Irrigated & Favorable & Mauritania, Niger \\
& Rainfed & Drought- and submergence-prone & Nigeria, Senegal \\
& Deepwater & Drought- and submergence-prone & Chad, Mali \\
& Mangeove swamp (Tideland) & Submergence & Gambia, Guinea-Bissau \\
\hline
\end{tabular}


A

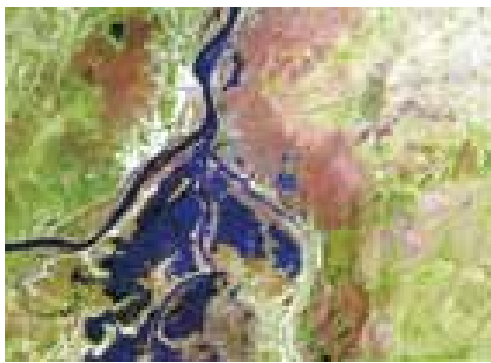

B

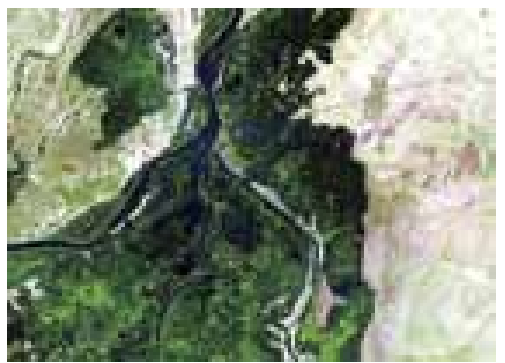

Fig. 2. Estimation of flooded area by LANDSAT-ETM+ at Niger delta in 2000 to 2001. A; the beginning of flood (August 26), B; heading stage of rice (October 29), C; after harvesting of rice (January 1)

regime. Therefore, damage to rice plants by submergence differs depending on the distinctive water environments, which are determined by water depth, duration of submergence, temperature, turbidity, rate of nitrogen fertilizer, and light intensity (Palada and Vergara 1972). In flooded areas, rice is vulnerable to submergence by erratic heavy rains. The young seedlings can be damaged severely by complete submergence. The rainfed lowland ecosystem is defined as rice cultivation with 5-50 $\mathrm{cm}$ of standing water (Mackill et al. 1996). Rainfed lowlands have various types according to topographic characteristics such as coastal areas, river line, and inland valleys in West Africa. Rainfed lowland, deepwater, and mangrove swamp ecosystems occupy over $33 \%$ of the rice cultivation area from Senegal to Sierra Leone in the Guinea gulf and Nigeria (Balasubramanian et al. 2007). Deepwater ecosystems occupy more than $50 \%$ of ricecultivated areas in Mali, Niger, and Chad.

A tideland is present in the coastal area from Nigeria to Senegal. This tideland is flooded by heavy rains and drains badly, engendering a rapid surge of the water level in paddy fields. In coastal areas, mangrove swamps are prevalent and rice plants are influenced by the tide. In the dry season, the salinity level becomes very high in the mangrove swamp. However, flooding water washes away the salt. Thereafter, rice can be cultivated during the rainy season (Norman and Otoo 2003). The flooding water level reaches above $1 \mathrm{~m}$ in August in the flood-plains in Guinea: boats are necessary to go to the fields. The inland area beside the coastal area has low salinity, but it drains badly. At the beginning of the rainy season, the rainfall is erratic. Therefore, young seedlings in the nursery or in the process of transplanting become withered or conversely perish because of the submergence caused by the erratic heavy rain. For that reason, most farmers prefer to transplant large seedlings whose shoot height is greater than $50 \mathrm{~cm}$

Inland delta areas are formed beside rivers which pass in the inland of African continent. The Niger River, whose total length is $4200 \mathrm{~km}$ from Guinea to the Gulf of Nigeria, flows through Mali and Niger. A huge inland delta area is formed by the river (Fig. 2). The precipitation is from only 140 to $700 \mathrm{~mm}$ in Niger and Mali, and the increase in water level at the delta shows no correlation with precipitation. The precipitation in the forest region in Guinea, the origin of the river, affects the floods in the delta in Mali and Niger. The water level starts to increase from mid-August to mid-September and reaches its maximum in mid-October to mid-November in Mali (Catling 1992). The submergence continues for 4-5 months in the delta. The average increase in water level is $5-8 \mathrm{~cm}$ per day, and the maximum increase can be as high as $10 \mathrm{~cm}$ per day, creating river water depths of 2.5$3 \mathrm{~m}$ (Bidaux 1971).

In the gradually undulating plain or plateau in West Africa and Central Africa, there are lowland areas in small valleys called inland valleys (Andriesse 1986). In the valley bottom, small streams are formed by water from upland areas and the upper reaches of major and minor watersheds. The stream becomes larger as it flows to its junction with the main river. Inland valleys are classifiable mainly into two types from a hydrological viewpoint: upper reaches and downstream of watersheds (Saviddes 1981). In those valleys, the paddy fields have no bounds, and rice is planted along the stream. Under these circumstances, rice plants are submerged easily by flash floods caused by heavy rains. However, the flood waters recede within a few days after the rain stops in those valleys. In the valley bottom, perennial rivers are formed by water stored in the upper reaches, and join the main river. The floodplain is formed in the confluence area, and rice plants in these areas are submerged by inundation of 
water from the main river.

\section{Submergence responses to rice plants}

The strategic measures that rice plants employ to survive submergence vary according to submergence of varying water level and duration of the submergence. A floating rice area is defined as that with continuous presence of 1-6 $\mathrm{m}$ of the water level during at least half of the rice growing period (DeDatta 1981). Deepwater areas are marked by the continuous presence of $0.2-1 \mathrm{~m}$ of water for longer than 1 month, within which an intermediatedeepwater area exists $(20-50 \mathrm{~cm})$. Shallow to deep, submergence-prone areas are defined as areas that are submerged for short periods (Mackill et al. 1996). However, it is difficult to use this classification system to describe the environments in West Africa. For example, the submergence level is typically around $50 \mathrm{~cm}$ in most lowland coastal regions in Guinea. Therefore, it is not necessary to divide the deepwater area into intermediate and deepwater areas. For the discussions presented in this paper, a floating rice area is defined as an area in which only floating rice can survive at a water level above about $1 \mathrm{~m}$ for a certain period. The deepwater area is defined as an area in which modern rice varieties, which are characterized as semi-dwarfs, cannot survive because of the prolonged period of deeper submergence. Flash flood areas are defined as areas where modern rice varieties can be planted but which are prone to be damaged by short-term submergence caused by flash floods. Floating rice areas are found in the inland delta of the Niger River. Deepwater areas can be found near coastal regions and the inland delta. Flash flood areas are found in coastal and inland valley regions.

\section{Growth response to short-term complete submergence}

Mechanisms in cultivars that are intolerant to short-term complete submergence include active shoot elongation and reorientation of leaves with hormonal regulation, with consequent rapid reallocation of carbon to newly developing leaves during submergence, which causes plants to exhaust carbohydrates (Sakagami et al. 2010). However, tolerant cultivars are characterized by conservation of energy and carbohydrate and leaf acclimation by changed photosynthesis. Consequently, submerged plants use photosynthetic products stored before submergence effectively during submergence. These contrasting responses affect survival and adaptation to aerobic conditions at post-submergence. Most rice plants show rapid shoot elongation in response to submergence. Shoot elongation enables rice plants to resume aerobic metabolism and photosynthetic fixation of $\mathrm{CO}_{2}$ by raising their shoots above the water surface (Ram et al. 2002, Jackson and Ram 2003). The rate of gas exchange is very slow in water because of small diffusion coefficients for gases (oxygen, $0.201 \mathrm{~cm}^{-2} \mathrm{~s}^{-1}$ in air; $2.1 \times$ $10^{-5} \mathrm{~cm}^{-2} \mathrm{~s}^{-1}$ in water) (Armstrong 1979). When water becomes stagnant, the concentration of oxygen becomes low at night because of the nighttime algal respiration (Fig. 3). Rice plants increase the rate of alcoholic

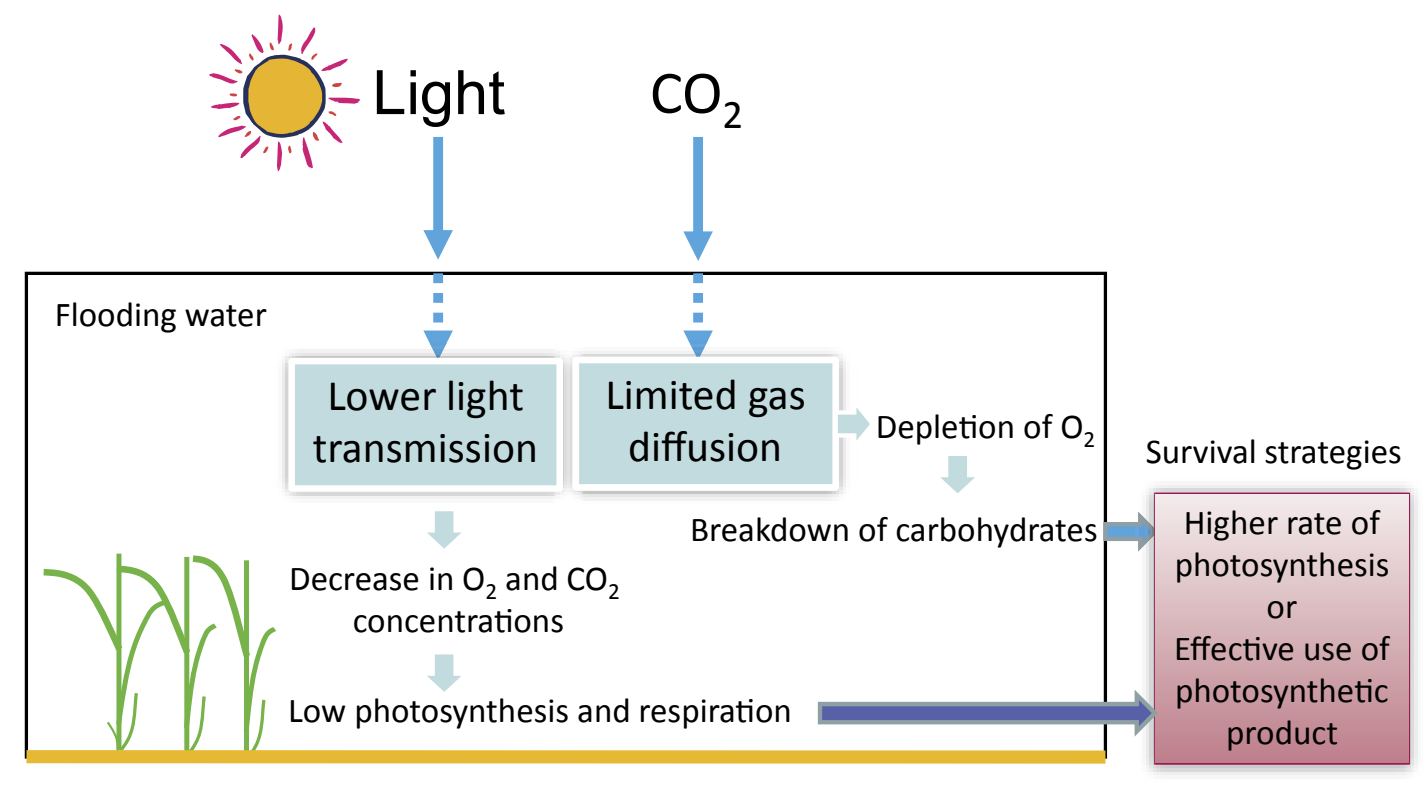

Fig. 3. Rice plants under stagnant floodwater 

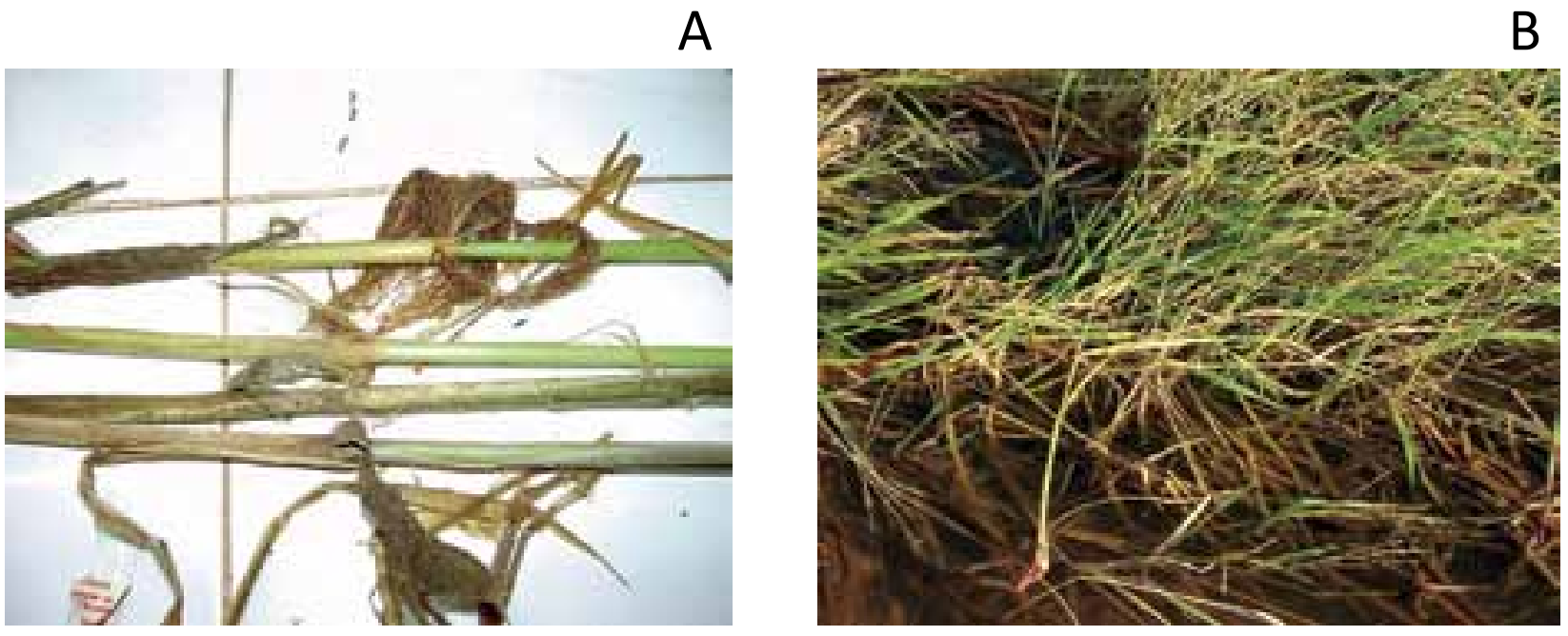

Fig. 4. Life cycle of floating rice in flood-prone region in West Africa. (A) Internodal elongation at heading key characteristic (B) kneeing at maturity

fermentation under low-oxygen environments. However, alcoholic fermentation produces only two molecules of ATP per glucose molecule. It is not efficient when compared with aerobic respiration, where 32 molecules of ATP are produced per glucose molecule. Therefore, rice cannot survive in a low-oxygen environment for a long period because of the shortage of carbohydrates for energy production. Furthermore, photosynthesis is limited by low irradiance when the plant is submerged. It is necessary to improve the photosynthetic capacity and effective use of photosynthetic product as well to survive underwater. However, most rice cultivars escape from anaerobic environments by developing a canopy above the water surface for use in photosynthesis. Rice plants can also survive by restoring aerobic metabolism during submergence. However, during short-term submergence, such as that caused by flash floods, rapid leaf elongation adversely affects the plant recovery after desubmergence (Setter et al. 1997, Ito et al. 1999, Kawano et al. 2002). Strategies of rice to cope with submergence differ according to the water environment. Survival strategies of floating rice, deepwater rice, and flash-flood tolerant rice are discussed hereinafter.

\section{Growth response to prolonged submergence}

Floating rice propagates wildly along the major rivers in West Africa. The key characteristic of floating rice is its capabilities of internodal elongation (A) and kneeing (B) (Fig. 4). The elongation can be as great as $20-25 \mathrm{~cm}$ per day, and the height of some varieties can reach up to $6 \mathrm{~m}$
(DeDatta 1981). The kneeing capability can be described as the standing up of the upper parts of the stems when waters recede (Catling 1992). The photosensitivity of floating rice is high, and the growing period is 180-300 days. Sowing starts before flooding. Young rice seedlings are often susceptible to damage by drought because they grow under rainfed conditions. Furthermore, young rice seedlings do not possess sufficient ability to elongate in response to submergence, so this rice can be damaged by erratic heavy rains. The elongation capability of floating rice and deepwater rice appears at around one month after germination. Consequently, these rice varieties can adapt to submergence after that time (Takahashi 1988). The floating rice elongates internodes according to the water level to develop a canopy above the water surface. The effect of intermodal elongation appears in the main stem and old tillers during submergence (Catling 1992). When submergence continues, new tillers and roots are developed at the node of culms located near the water surface.

After the water level begins to recede, heading begins because the floating rice has the high photoperiodic-sensitivity and the time of flower initiation synchronizes with the end of the flooding season. The water environments at harvest are diverse: harvesting can occur at high levels of water or without water because the time of water recession depends on the climate and topography. When the waters recede, floating rice lies down. However, kneeing keeps the canopy and panicles erect and above the soil. To increase yields in rice of this type, it is important to increase the tiller number at the 
culms located near the surface of water and to increase the kneeing ability after the floodwaters subside. Deepwater rice is often characterized as floating rice. However, the differences in the characteristics of floating rice and deepwater rice are not yet understood clearly. In fact, the physiological mechanisms of growth differ between the two. Some rice plants can survive and stand without floating in water at water depths of $1 \mathrm{~m}$. For purposes of this discussion, the standing rice plants without floating in water are designated as deepwater rice to distinguish floating rice from deepwater rice. In general, the plant height of deepwater rice reaches 140$180 \mathrm{~cm}$ in the absence of submergence (Catling 1992). However, the capabilities of the deepwater rice shoot to extend are varied among cultivars. Deepwater rice can maintain aerobic metabolism during submergence via development of its canopy above water because of the elongation of its internodes and its long leaves. Deepwater rice's ability to elongate in a single day is less than that of floating rice. However, deepwater rice can adapt to submergence under conditions where the water level increases by $5 \mathrm{~cm}$ per day (Catling 1992). Nevertheless, tall plant architecture of this type often causes lodging after the water recedes. Therefore resistance to lodging is important for deepwater rice. In deepwater rice areas in Asia and Africa, the older seedlings ( $>50 \mathrm{~cm}$ height) are often transplanted to prevent complete submergence. Because of late transplanting, modern rice varieties exhibit a decreased number of tillers, which markedly decreases the yields. However, the yield of deepwater rice plants is largely unaffected by late transplantation (Mackill et al. 1996). This effect might result from recovery during the long duration of its vegetative stage. Therefore, the tall traditional varieties have been persistently cultivated in coastal areas in Guinea. O. glaberrima is originated in West Africa and cultivated in the Niger Delta. The cultivated area of $O$. glaberrima has been decreasing because of its low productivity. However, O. glaberrima is still cultivated in the Niger Delta today (Sakagami 1995). Sakagami et al. (2009) reported the high potential of photosynthesis in $O$. glaberrima underwater. The monocarpic $O$. glaberrima differs from that of $O$. sativa (Sakagami et al. 1999a, b). The unique characteristics of O. glaberrima remain important as a genetic resource. Nevertheless, the characteristics of $O$. glaberrima have not been studied sufficiently. Additional study is needed to improve the yield capacity to enlarge the rice cultivation field in flood-prone areas in West Africa.

\section{Flash flood tolerance}

Flash floods are defined as a rapid increase in water level, which causes partial to complete submergence for up to 2 weeks. Flash floods severely affect young rice seedlings, so improvement of flash flood tolerance in rice plants is extremely important. When rice plants are submerged by flash floods, they experience two different environmental changes: anaerobic conditions during submergence and aerobic conditions after desubmergence. Therefore, flash flood tolerant plants should be quickly adaptable to these two different environments (Ito et al. 1999). Most rice plants show shoot elongation in response to submergence as we described previously. This escape strategy adapts rice plants to long-term submergence in deepwater and floating rice areas. However, in short-term submergence circumstances such as those resulting from flash floods, rapid leaf elongation adversely affects the recovery of plants after desubmergence (Setter et al. 1997, Ito et al. 1999, Kawano et al. 2002). The negative relation between flash flood tolerance and shoot elongation during submergence was confirmed using the IRRI gene bank database to examine 903 cultivars (Setter and Laureles 1996). The cultivars or crossbreeds with vigorous elongation showed no tolerance at all. However, $49 \%$ of the total population which had low elongation score also showed poor submergence tolerance. Figure 5 portrays the recovery of completely submerged rice plants within 7 days after desubmergence in pot experiments conducted in Guinea. Shoot elongation was enhanced during submergence, but the plants were able to survive after desubmergence. Flash flood tolerant varieties show a limited amount of shoot elongation during submergence and good recovery after desubmergence. One cause of this phenomenon is differences in carbohydrate metabolism between shoot elongation and flash flood tolerant types (Ram et al. 2002, Jackson and Ram 2003, Setter et al. 1996, Ito et al. 1999). Photosynthesis decreases under complete submergence because of the shortage of $\mathrm{CO}_{2}$ and low irradiation, resulting in a decrease in the supply of carbohydrate. One adverse factor of shoot elongation is probably the increase in carbohydrate consumption for cell division, cell elongation, and maintenance of the elongating leaf (Setter and Laureles 1996, Ito et al. 1999, Voesenek et al. 2006). The limited availability of carbohydrates during submergence adversely affects the rice plants' recovery after desubmergence. One important factor for recovery after desubmergence is protection against oxidative stresses in aerobic environments after desubmergence 

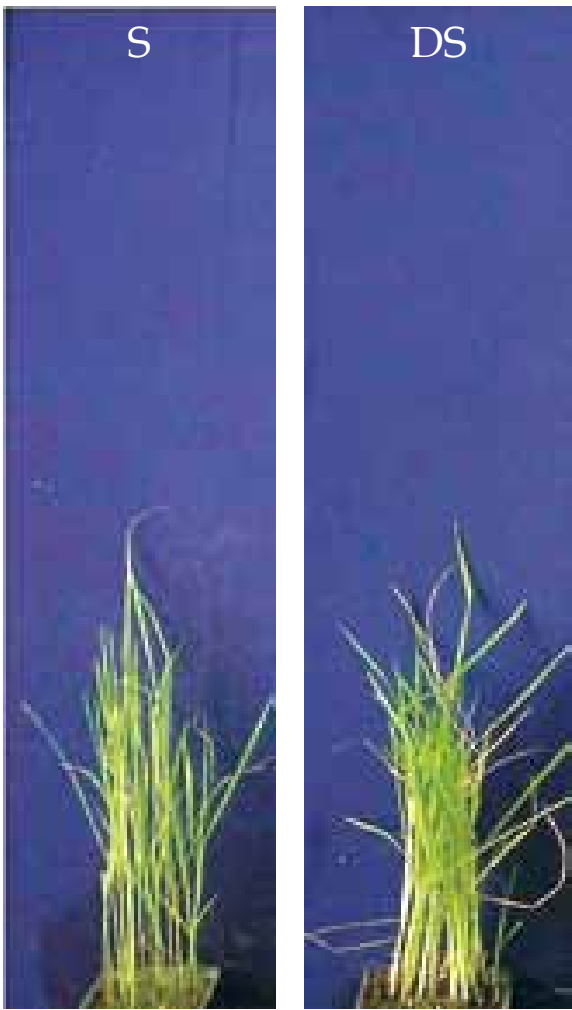

Flash floods-tolerant (IR49830)
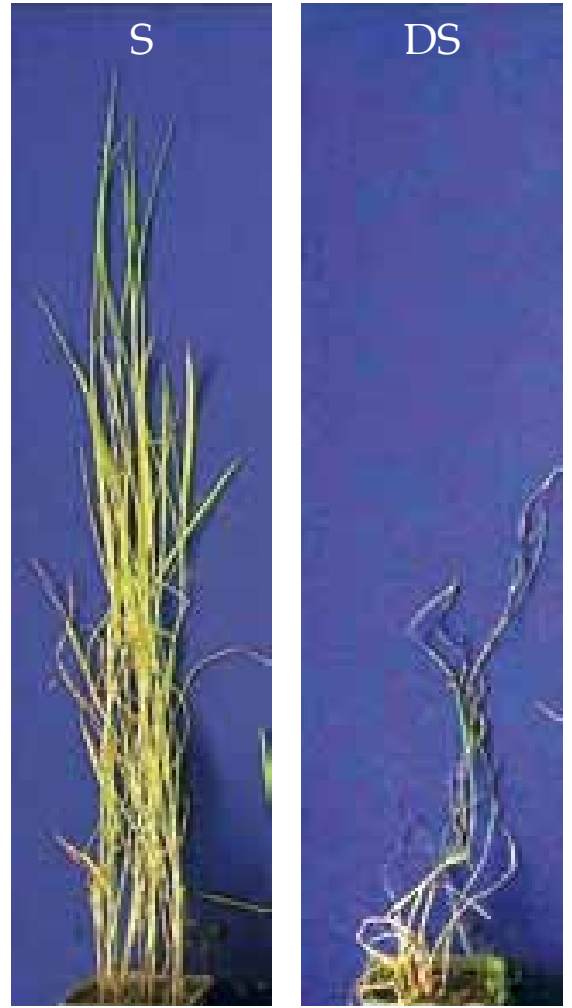

Shoot elongation (DouboutouII)

Fig. 5. Difference of the growth of flash floods-tolerant variety (IR49830) and shoot elongation variety (DouboutouII) at 1 day (S) and 14 days (DS) after desubmergence. Young rice seedlings were submerged completely for 7 days.

(Kawano et al. 2002). Ascorbic acid is a key antioxidant. Flash flood tolerant plants maintain higher levels of ascorbic acid compared to shoot elongation type plants during submergence, thereby limiting the damage by oxidative stress after desubmergence (Kawano et al. 2002). Adopting the quiescence strategy of not elongating quickly in response to submergence helps avoid lowering of the levels of available carbohydrates. This physiological trait most distinguishes so-called flash flood tolerant varieties. Flash flood tolerant rice conserves a stored carbohydrate before submergence in stems that might be used to recover from submergence after desubmergence
(Kawano et al. 2009).

\section{Physiological mechanisms of survival strategy under submergence conditions}

Rice has adapted to submergence-prone environments through two strategies: submergence tolerance to flash floods and shoot elongation to prolonged submergence (Table 2). This rapid shoot elongation is usually disadvantageous in flash flood conditions because lodging usually occurs once floodwaters recede. In tolerant varieties, this strategy of using cell elongation and

Table 2. Rice survival strategy under anaerobic condition

\begin{tabular}{|c|c|c|c|}
\hline Type & Tolerance & \multicolumn{2}{|c|}{ Escape } \\
\hline Rice growing environment & Flash Floods less than 2 weeks & $\begin{array}{l}\text { Short to long-term floods with } \\
\text { shallow water }\end{array}$ & $\begin{array}{l}\text { Long-term floods with deep } \\
\text { water }\end{array}$ \\
\hline $\begin{array}{l}\text { Eco-physiological mechanism } \\
\text { for survival strategy }\end{array}$ & $\begin{array}{l}\text { Slowing of ethylen-promoted } \\
\text { leaf elongation to conserve } \\
\text { energy }\end{array}$ & $\begin{array}{l}\text { Rapid leaf elongation by LOES } \\
\text { (Low Oxgen Escape Syndrome) } \\
\text { to restore contact between } \\
\text { leaves and air }\end{array}$ & $\begin{array}{l}\text { Rapid internodal or stem } \\
\text { elongation to resume anaerobic } \\
\text { metabolism and photosynthesis }\end{array}$ \\
\hline Conservation of carbohydrate & High & Low & Low \\
\hline Rice ecotype & Quiscence rice & Shoot elongating rice & Deepwater rice, floating rice \\
\hline
\end{tabular}


heightened carbohydrate metabolism is repressed. Furthermore, rapid elongation by Low Oxygen Escape Syndrome (LOES) can restore contact between leaves and air but can also result in death if carbohydrate reserves are depleted before emergence in leaves above the water surface. This mechanism is expected to be effective when flood waters become shallow. Leaf elongation during submergence is controlled by the interaction of at least three plant hormones: ethylene, GA, and ABA (Kende et al. 1998). Accumulated ethylene is probably the primary signal that triggers the plant to start a cascade of reactions leading to enhanced cell elongation (Voesenek et al. 2006) because ethylene is accumulated in rice plants during submergence as a result of the fact that gas diffusion is $10^{4}$-fold slower in a liquid solution (in this case water) than in air (Armstrong 1979). The cascade model was proposed from a study of stem elongation in deepwater rice (Kende et al. 1998). The proposed chain reactions are as follows: first, the accumulated ethylene reduces ABA levels; second, the reduced $A B A$ level engenders increased responsiveness of GA; and lastly, GA promotes stem elongation. These mechanisms are controlled genetically. $\mathrm{Xu}$ and Mackill (1996) revealed that a single locus on chromosome 9, designated as $S u b 1$, is responsible for most of the submergence tolerance derived from the flash floodtolerant parent: FR13A. Map-based QTL analysis revealed that a major QTL for shoot elongation and the maintenance of green leaves during submergence and plant recovery after desubmergence is located on chromosome 9. The flash flood tolerant FR13A parent contributes the trait for the suppression of shoot elongation, maintenance of green leaves, and plant recovery after desubmergence to the offspring (Ram et al. 2002). Flash flood tolerant varieties with $S u b 1$ showed good performance amidst flash floods in the paddy fields in Guinea (Kawano et al. 2009), thereby showing that $S u b 1$ genes are effective in West Africa. Hattori et al. (2009) detected SNORKEL1 and SNORKEL2 as deepwater responses gene for elongation for escape from long-term floods.

\section{Evolution of flood-plain rice cultivation in West Africa}

The study of submergence resistance in rice started in Rokpur in Sierra Leone in 1934. Two lines, ROK5 and ROK14, were developed to be adapted, respectively, to lowland coastal areas and inland areas, and to lowland inland areas. The International Institute of Tropical
Agriculture (IITA) and the West Africa Development Association (WARDA) were established, respectively, in 1965 and 1971 with the purpose of introducing floating rice and deepwater rice of $O$. sativa from Asia to Africa because, at that time, no rice variety had adapted to submergence in Africa. Upland NERICA, consisting of the interspecific hybridization of $O$. sativa and $O$. glaberrima, was developed by Africa Rice Center (WARDA) in 1996. Recently, lowland NERICA has been developed and its use is now expanding. However, the development of rice varieties adapted to rainfed lowland and deepwater rice area has been given less attention, even though areas of these types account for most of the rice cultivation area in Africa. Therefore, it is important to develop rice varieties that are adapted to rainfed lowlands to increase rice cultivation self-sufficiency. Particularly, the adaptability of $O$. glaberrima to deepwater rice areas is an important developmental target. The introduction of the Sub-1 gene to lowland NERICA varieties is also crucial to establishing stable rice production in rainfed lowland regions in Africa.

Rice cultivation in Africa is no longer restricted to any specific region. Therefore, it is not a site-specific agricultural system. Instead, it already occupies an extremely important position in agricultural development in Africa. Although traditional upland rice is dominating the rice cultivation system in West Africa, lowland rice has recently come under the spotlight to increase the use of wetlands that are distributed widely throughout the region and which are regarded as advantageous in terms of water control over upland rice. From that perspective, it is extremely important to collect information related to characteristics of rainfed lowland rice cultivation in West Africa. We previously studied the rice production potential of traditional cultivation in the inland delta of the Niger River in Mali, which is described in another paragraph (Sakagami et al. 2008). Our investigation showed that the traditional rice cultivation system of the inland delta depends more on flooded water from the Niger River than the rainfall that occurs in the area. We demonstrated also that $O$. glaberrima, which is widely cultivated in the area, should be a cultivated species that is highly adapted to local conditions considering its growth characteristics. Particularly it has been recently understood that African rice is similar to the indica type of $O$. sativa in terms of its cooking quality. Both have properties of starch that result in a firm and non-sticky texture immediately after cooking and cooling. Crop management practices here are characterized by low input technology, where weed control and soil fertility management are conducted using 
the best use of flooding, which suppresses weed germination and which brings fertile soils from adjacent upstream areas. Furthermore, it is suggested that total nitrogen in flooded soil of the inland delta is comparatively higher than those of other flooded areas in Africa (Buri et al. 1999). In fact, farmers grow rice using no chemical fertilizers. However, to adopt those above described low input technologies, it is prerequisite that submerged water conditions are maintained for a certain period of time. In this flooding region, it is important to develop a prediction model to cover a flooded area and high-performance rice genotypes for stable rice production in the future.

\section{CONCLUSION}

Rice production is unstable in Africa because most rice is cultivated in rainfed ecosystems. Rice cultivation is vulnerable to drought and submergence caused by climate variability. Stable agricultural systems should be established by mitigating the effects of natural disasters. Recently, rice cultivation has shifted from upland to lowland varieties because of the higher yields of the latter. However, rice plants in flash flood prone areas and river basin suffer from excess water stress caused by heavy rains and inundation. The development of new cultivation methods and tolerant genotypes is necessary in such areas to prevent damage caused by excessive water stress. O. glaberrima, which is adapted to floating rice and deepwater rice areas, is still cultivated in the Niger Delta. The potential adaptability of $O$. glaberrima is important for genetic improvement. The development of rice cultivation in the inland valley regions is also anticipated in Africa but rice often suffers from flash floods in these regions. A possible solution for plant improvement is the $S u b-1$ gene, which has demonstrated its efficiency against flash floods in Guinea. A Sub-1transformed lowland genotype might contribute to stabilizing rice production in flash flood-prone regions. Another solution is to establish a prediction model for flooded areas to escape damage along the river through hydrologic analyses. Additionally, we would like to emphasize the high potentiality of flood-plain areas along major rivers in West Africa for rice production on the grounds that rice plants grow well with suitable soil fertility, water availability, and cultivars.

\section{REFERENCES}

Africa Rice Center. 2004. Breaking story - Going beyond the upland NERICA: another New Rice for Africa is born. In: Annual Report 2003-2004. Cotonu, Benin. 14-19.

Andriesse W. 1986. The Wetlands in sub-Saharan Africa. In: The Wetlands and Rice Subsaharan Africa: Proceedings of an International Conference on Wetland Utilization for Rice Production in SubSaharan Africa, (eds. Juo ASR, Lowe JA.) IITA, Ibadan, 15-30.

Armstrong W. 1979. Aeration in higher plants. Advanced Botanical Research 7: 225-331.

Asubonteng K, Kobota D, Hayashi K, Masunaga T, Wakatsuki T. 2001. Characterization and evaluation of inland valley watersheds for sustainable agricultural production: case study of semideciduous forest zone in the Ashanti region of Ghana. Tropics 10: 539-533.

Balasubramanian V, Sie M, Hijmans RJ, Otsuka K. 2007. Increasing rice production in Sub-Saharan Africa: Challenges and opportunities. Advances in Agronomy 94: 55-133.

Bidaux JM. 1971. La riziculture en eau profonde au Mali. L'Agronomie tropicale 26: 1100-1114. [in French].

Buri MM, Ishida F, Kubota D, Masunaga T, Wakatsuki T. 1999. Soils of flood plains of West Africa: general fertility status. Soil Science and Plant Nutrition 45: 37-50.

Catling D. 1992. Rice in Deep Water. Macmillan, London.

Chu YE, Oka HI. 1972. The distribution and effects of genes causing F1 weakness in Oryza breviligulata and $O$. glaberrima. Genetics 70: 163-173.

DeDatta SK. 1975. Upland rice around world. In: Major research in upland rice. IRRI, Los Banos. 2-11.

DeDatta SK. 1981. Systems of rice culture. In Principles and Practices of Rice Production. J. Wiley and Sons, New York. 221-258.

Futakuchi K. 2005. Submergence damage in rice and challenges in expanding the crop's adaptability to submerged conditions in West and Central Africa. Japanese Journal of Crop Science 74 (Extra issue 2): 258-259.

Hallegatta S, Ranger N, Bhattacharya S, Bachu M, Priya S, Dhore K, Rafique F, Mathur P, Naville N, Henriet F, Patwardhan A, Narayanan K, Ghosh S, Karmakar S, Patnaik A, Abhayankar A, Pohit S, Morlot-Corfee J, Herweijer C. 2010. Food risk, climate change impacts and adaptation benefits in Mumbai: An 
initial assessment of socio-economic consequences of present and climate change induced flood risks and of possible adaptation. OECD Environment Working Papers No. 27. OECD, Paris.

Hattori Y, Nagai K, Suzuki F, Song XJ, Kawano R, Sakakibara H, Wu J, Matsumoto T, Yoshimura A, Kitano H, Matsuoka M, Ashikari M. 2009. The ethylene response factors SNORKEL1 and SNORKEL2 allow rice to adapt to deep water. Nature 460: 1026-1030.

Ito O, Ella E, Kawano N. 1999. Physiological basis of submergence tolerance in rainfed lowland rice ecosystem. Field Crops Research 64: 75-90.

Jackson MB, Ram PC. 2003. Physiological and molecular basis of susceptibility and tolerance of rice plants to complete submergence. Annals of Botany 91: 227241.

Jackson MB. 2008. Ethylene-promoted elongation: an adaptation to submergence stress. Annals of Botany 101: 229-248.

Kadomura H. 2005. In 2003, including heavy rains and floods that occurred during northern hemisphere summer. African Study Monographs 30: 165-181.

Kawano N, Ella E, Ito O, Yamauchi Y, Tanaka K. 2002. Metabolic changes in rice seedlings with different submergence tolerance after desubmergence. Environmental and Experimental Botany 47: 157-203.

Kawano N, Ito O, Sakagami JI. 2009. Morphological and physiological responses of rice seedlings to complete submergence (flash flooding). Annals of Botany 103: 161-169.

Kende H, Van der Knaap E, Cho HT. 1998. Deepwater rice: a model plant to study stem elongation. Plant Physiology 118: 1105-1110.

Mackill DJ, Coffman WR, Garrity DP. 1996. Agronomic traits. In: Rainfed Lowland Rice Improvement, (eds. Mackill DJ, Coffman WR, Garrity DP.) Los Banos, Philippines: International Rice Research Institute, 49-64.

Nicholson SE. 2009. A revised picture of the structure of the "monsoon" and land ITCNZ over West Africa. Climates Dynamics 32: 1155-1171.

Norman JC, Otoo E. 2003. Rice development strategies for food security in Africa In: Sustainable rice production for food security: Proceedings of the $20^{\text {th }}$ Session of the International Rice Commission. Bangkok, 23-26 July 2002. 235-250.

Palada MC, Vergara BC. 1972. Environmental effects on the resistance of rice seedlings to complete submergence. Crop Science 12: 209-212.
Porteres R. 1970. Primary cradles of agriculture in the Africa continent. In: Paper in African Prehistory. (eds. Fage J, Oliver R.) Cambridge University Press, Cambridge, 43-58.

Ram PC, Singh BB, Singh AK, Ram P, Singh PN, Singh HP, Boamfa EI, Harren FJM, Santosa E, Jackson MB, Setter TL, Reuss J, Wade LJ, Singh VP, Singh RK. 2002. Submergence tolerance in rainfed lowland rice: physiological basis and prospects for cultivar improvement through marker-aided breeding. Field Crops Research 76: 131-152.

Sakagami JI. 1995. Traditional rice cultivation and cultivar in Niger, Agriculture and Horticulture 70: 28-34 [in Japanese].

Sakagami JI, Isoda A, Nojima H, Takasaki Y. 1999a. Growth and survival rate after maturity in Oryza sativa L. and $O$. glaberrima Steud. Japanese Journal of Crop Science 68: 257-265.

Sakagami JI, Isoda A, Nojima H, Takasaki Y. 1999b. Annuality and perenniality characteristics and variation in Oryza sativa L. and O. glaberrima Steud. Japanese Journal of Crop Science 68: 524-530

Sakagami JI, Hatta T, Kamidozono A, Masunaga T, Umemoto T, Uchida S. 2008. The actual condition of traditional rice culture in inland valley delta of Niger River. In: Forefront of rice cultivation in Africa, (eds. Sakagami JI, Ito O.) JIRCAS Working Report No.57, 37-52.

Sakagami JI, Joho Y, Ito O. 2009. Contrasting physiological responses by cultivars of Oryza sativa and $O$. glaberrima to prolonged submergence. Annals of Botany 103: 171-180.

Sakagami JI, Ito O, Sone, C. 2010. Submergence tolerance with mechanisms of translocation of photosynthetic product during early rice seedling in Africa. Third International Rice Congress, 4239.

Saviddes L. 1981. Guidelines to improving valley swamps (fadamas). In A Procedure and Approach Followed in the Bida Agricultural Development Project. BADP, Bida, 64.

Setter TL, Laureles EV. 1996. The beneficial effect of reduced elongation growth on submergence tolerance of rice. Journal of Experimental Botany 47: 1551-1559.

Setter TL, Ellis M, Laureles EV, Ella ES, Senadhira D, Mishra SB, Sarkarung S, Datta S. 1997. Physiology and genetics of submergence tolerance in rice. Annals Botany 79: 67-77.

Sultan B, Janicot S. 2000. Abrupt shift of the ITCZ over West Africa and intra-seasonal variability. 
Geographysical Research Letters 27: 3353-3356.

Takahashi K. 1988. Hormonal regulation of internode elongation in rice shoots. In: Proceedings of the International Deepwater Rice Workshop. IRRI, Los Banos. 245-255.

Voesenek LACJ, Colmer TD, Pierik R, Millenaar FF, Peeters AJM. 2006. Tansley review. How plants cope with complete submergence. New Phytologist 170: 213-226.

Xu K, Mackill DJ. 1996. A major locus for submergence tolerance mapped on rice chromosome 9. Molecular Breeding 2: 219-224.

Received $16^{\text {th }}$ May 2011

Accepted 22 ${ }^{\text {nd }}$ Sep. 2011 